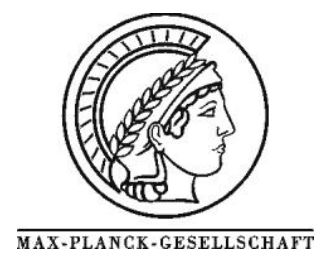

Journal of Catalysis 269 (2010), 309-317

\title{
Methanol oxidation over model cobalt catalysts: Influence of the cobalt oxidation state on the reactivity
}

\author{
S. Zafeiratos ${ }^{\text {a,* }}$, T. Dintzer ${ }^{\text {a }}$, D. Teschner ${ }^{\text {b }}$, R. Blume ${ }^{\text {b }}$, M. Hävecker ${ }^{\text {b }}$, A. Knop-Gericke ${ }^{\text {b }}$, R. Schlögl ${ }^{\text {b }}$ \\ ${ }^{a}$ LMSPC, UMR 7515 du CNRS, 25 Rue Becquerel, 67087 Strasbourg, France \\ ${ }^{b}$ Fritz-Haber-Institut der Max-Planck-Gesellschaft, Faradayweg 4-6, 14195 Berlin, Germany \\ * Corresponding author: e-mail spirosz@ecpm.u-strasbg.fr (S. Zafeiratos).
}

Received 20 July 2009; Revised 1 October 2009; Accepted 12 November 2009

\begin{abstract}
X-ray photoelectron and absorption spectroscopies (XPS and XAS) combined with on-line mass spectrometry were applied under working catalytic conditions to investigate the methanol oxidation on cobalt. Two cobalt oxidation states $\left(\mathrm{Co}_{3} \mathrm{O}_{4}\right.$ and $\left.\mathrm{CoO}\right)$ were prepared and investigated as regards their influence on the catalytic activity and selectivity. In addition adsorbed species were monitored in the transition of the catalyst from the non-active to the active state. It was unequivocally shown that the surface oxidation state of cobalt is readily adapted to the oxygen chemical potential in the $\mathrm{CH}_{3} \mathrm{OH} / \mathrm{O}_{2}$ reaction mixture. In particular, even in rich to oxygen mixtures the $\mathrm{Co}_{3} \mathrm{O}_{4}$ surface is partially reduced, while the degree of surface reduction is higher as the methanol concentration in the mixture increases. The reaction selectivity depends on the cobalt oxidation state with the more reduced samples favouring the partial oxidation of methanol to formaldehyde. In the absence of oxygen, methanol is effectively reducing cobalt to the metallic state, promoting also hydrogen and CO production. Direct evidence of methoxy and formate species adsorbed on the surface upon reaction was found by analysing the $\mathrm{O} 1 \mathrm{~s}$ and $\mathrm{C}$ 1s photoelectron spectra. However, the surface coverage of those species was not proportional to the catalytic activity, indicating that in the absence of surface oxygen, these species might act also as reaction inhibitors.
\end{abstract}

Keywords: Cobalt catalyst; Cobalt oxides; Methanol oxidation; In situ XPS; In situ XAS; Reaction intermediates; Fischer-Tropsch synthesis

\section{Introduction}

Our current understanding of heterogeneous catalysis is to a large extent built on post-reaction (ex-situ) analysis of the catalysts and deductions based on kinetic experiments. A key problem was the lack of surface-sensitive techniques that could provide spectroscopic information at pressures relevant to the catalysis process. The situation in catalyst characterization is progressively changing, and today a variety of techniques are available that may provide detailed atomic-scale structural and chemical insight into complex heterogeneous catalysts exposed to controlled environments that closely match the working conditions $[1,2,3]$. These studies showed that the structure of a heterogeneous catalyst is dynamic and depends intimately on the reaction conditions. Such dynamic changes have, for example, been observed on a $\mathrm{Cu}$ and $\mathrm{Ru}$ catalyst during methanol oxidation, indicating that the active state of the catalyst exists only during the process of catalysis $[4,5,6,7]$.
Cobalt and its oxides $\left(\mathrm{CoO}\right.$ and $\left.\mathrm{Co}_{3} \mathrm{O}_{4}\right)$ exhibit interesting electronic and magnetic properties and are used as catalysts in a range of reactions. Perhaps the major application of cobalt-based catalysts is in the Fischer-Tropsch synthesis, since cobalt has been shown to efficiently convert syn gas $\left(\mathrm{CO}+\mathrm{H}_{2}\right)$ to methane or liquid fuels $[8,9,10,11]$. Other applications of cobalt catalysts include partial oxidation reactions [12] and decomposition of methane to form hydrogen and carbon nanotubes or filamentous carbon $[13,14]$. Recently cobalt has been proposed as a very promising catalyst to replace noble metals for $\mathrm{H}_{2}$ production by steam reforming of ethanol $[15,16]$. Pure cobalt oxide surface phases have been scarcely investigated with respect to their catalytic properties $[17,18,19]$ and always by $e x$-situ methods. While this has provided valuable information it is still an open question whether the active surface state "survive" after reaction. As it was previously demonstrated for the $\mathrm{Cu}$ and $\mathrm{Ru}$ catalysts [4,5] dynamic 
variations of the surface under working conditions may play a vital role in the catalytic functionality.

In the present work, high pressure photoelectron and soft x-ray absorption spectroscopy are applied under working catalytic conditions, to investigate methanol oxidation reaction on cobalt. Acquiring fundamental understanding of the reaction networks of methanol on cobalt is important for further development of processes such as methanol synthesis from syngas, production of formaldehyde and for operation of direct methanol fuel cells. On the other hand, methanol may also serve as a simple model compound for the study of the oxidation of other more complex alcohols like ethanol and glycerol [20]. The aim of this work is to probe if cobalt undergoes dynamic variations under reaction conditions and to understand the role of different cobalt oxidation states to the reaction pathways.

\section{Experimental}

In situ x-ray photoelectron and absorption spectroscopy (XPS and XAS respectively) were performed at ISISS beamline at BESSY in Berlin, in a setup described elsewhere $[2,4]$. The soft X-ray absorption spectra of the Co $\mathrm{L}_{3,2}$ edges were recorded in the Total Electron Yield (TEY) mode, enhanced by additional electrons created by ionization of the gas phase above the sample. The $0.5 \mathrm{~mm}$ thick and $5 \mathrm{~mm}$ diameter Co (0001) single crystal was placed on a sample holder, which could be heated from the rear by an IR laser (cw, $808 \mathrm{~nm}$ ). The temperature was measured by a K-type thermocouple fixed on the sample surface. The Co crystal was pre-treated in the XPS reaction cell by oxidation $\left(0.2 \mathrm{mbar}_{2} \mathrm{O}_{2}\right.$ at $\left.520 \mathrm{~K}\right)$ and reduction $\left(0.2 \mathrm{mbar}_{2}\right.$ at $520 \mathrm{~K}$ ) cycles, until all residual surface carbon disappeared. The same procedure was repeated after each reaction cycle to "refresh" the surface. The reaction mixture was introduced after cooling down the sample at $300 \mathrm{~K}$ with an overall pressure of 0.1 to 0.3 mbar. Consequently the sample was heated to $520 \mathrm{~K}$ (by $5 \mathrm{~K} / \mathrm{min}$ ) where photoemission and absorption spectra were recorded. Preparation of $\mathrm{Co}_{3} \mathrm{O}_{4}$ and metallic Co surfaces was attained after 30 min annealing in 0.2 mbar $\mathrm{O}_{2}$ and $\mathrm{H}_{2}$ respectively, at $520 \mathrm{~K}$. The $\mathrm{CoO}$ surface was formed by heating metallic $\mathrm{Co}$ at $450 \mathrm{~K}$ in 0.2 mbar $\mathrm{H}_{2}$ and consequently introducing traces of $\mathrm{O}_{2}(\sim 5-$ $10 \%$ of the hydrogen pressure). Few minutes under these conditions were adequate to form a thick $\mathrm{CoO}$ layer on the Co crystal, as judged by XPS.

$\mathrm{CH}_{3} \mathrm{OH}, \mathrm{O}_{2}$ and $\mathrm{H}_{2}$ gas flow into the reaction cell was controlled using calibrated mass flow controllers. A differentially pumped quadrupole mass spectrometer (QMS) was connected through a leak valve to the experimental cell and the gas phase composition was monitored by on-line mass spectrometry simultaneously to the spectroscopic characterization of the surface. The decrease of $\mathrm{CH}_{3} \mathrm{OH}(\mathrm{m} / \mathrm{e}=31)$ QMS intensity was used to calculate $\mathrm{CH}_{3} \mathrm{OH}$ conversion under reaction conditions. Relative product selectivities were calculated by the increase of the $\mathrm{H}_{2}(\mathrm{~m} / \mathrm{e}=2), \mathrm{CO}(\mathrm{m} / \mathrm{e}=28), \mathrm{CH}_{2} \mathrm{O}(\mathrm{m} / \mathrm{e}=30)$ and $\mathrm{CO}_{2}$ $(\mathrm{m} / \mathrm{e}=44) \mathrm{QMS}$ intensities induced by the catalytic reaction. A correction of the ion current signals of $\mathrm{m} / \mathrm{e}=28$ and 30 due to $\mathrm{CH}_{3} \mathrm{OH}$ fragment ( 20 and $25 \%$ of $\mathrm{m} / \mathrm{e}=31$ respectively) was also taken into account. It should be noted that, since QMS signals are not calibrated to the sensitivity factor of each gas, only the comparison of selectivities between various conditions is considered here.

Photoemission spectra were recorded both during temperature rising and stationary conditions. Two methanol-to-oxygen mixing ratios (MR) $1: 5$ and 2:1, were studied and are referred here as $\mathrm{MR}=0.2$ and 2 respectively. The Co 2p, O 1s and C 1s spectra were recorded using appropriately selected photon energies, resulting photoelectrons with two characteristic kinetic energies for each spectrum, namely 180 and $580 \mathrm{eV}\left(\lambda_{[180 \mathrm{eV}]} / \lambda_{[580 \mathrm{eV}]}=0.56\right.$, where $\lambda$ is the photoelectron attenuation length) [21]. In that way, information of two different depths was collected providing a non destructive depth analysis. For the calculations all spectra were normalized by the storage ring current and the energy dependent incident photon flux, which was measured prior to the measurements using a gold foil with known quantum efficiency. The photon flux obtained has been corrected for higher diffraction orders that contribute only to the background but not to the peak intensity in XPS. The spectra presented here are rescaled to facilitate the observation of peak characteristics. The binding energy (BE) scale was calibrated with respect to the Fermi level of the electron analyzer. The oxidized surface showed no electrostatic charging. Curve fitting of the $\mathrm{O} 1 \mathrm{~s}$ and $\mathrm{C} 1 \mathrm{~s}$ peaks was performed based on a mixed Gaussian/Lorentzian function. XPS and XAS peaks of Co were fitted using line shapes recorded on reference samples. Background subtraction was carried out by using the Shirley method. Quantitative calculations were performed using normalized Co $2 p$, $\mathrm{O} 1 \mathrm{~s}, \mathrm{C} 1 \mathrm{~s}$ intensities, taking into account the photonenergy dependence of the atomic subshell photoionization cross sections [22].

\section{Results}

\subsection{The dynamic transformation of cobalt upon changes in the reaction mixture}

There are two stable bulk phases of cobalt oxide, i.e., the fcc-type rocksalt structure of $\mathrm{CoO}$ and the cubic spinel structure of $\mathrm{Co}_{3} \mathrm{O}_{4}$. The thermodynamically stable form of cobalt oxide under ambient temperature and pressure conditions is the $\mathrm{Co}_{3} \mathrm{O}_{4}$ spinel phase $[9,23]$. Therefore, initially we investigated how pre-oxidized cobalt surfaces respond to different reactant mixing ratios (MRs). Two MRs (0.2 and 2), as well as pure methanol, were studied at separate reaction cycles. Figure 1 displays photoemission and absorption spectra of Co $2 p$ core level $\left(\mathrm{L}_{3,2}\right.$ edge in absorption spectroscopy nomenclature) obtained from a cobalt crystal at $520 \mathrm{~K}$, under various gas phase environments. 

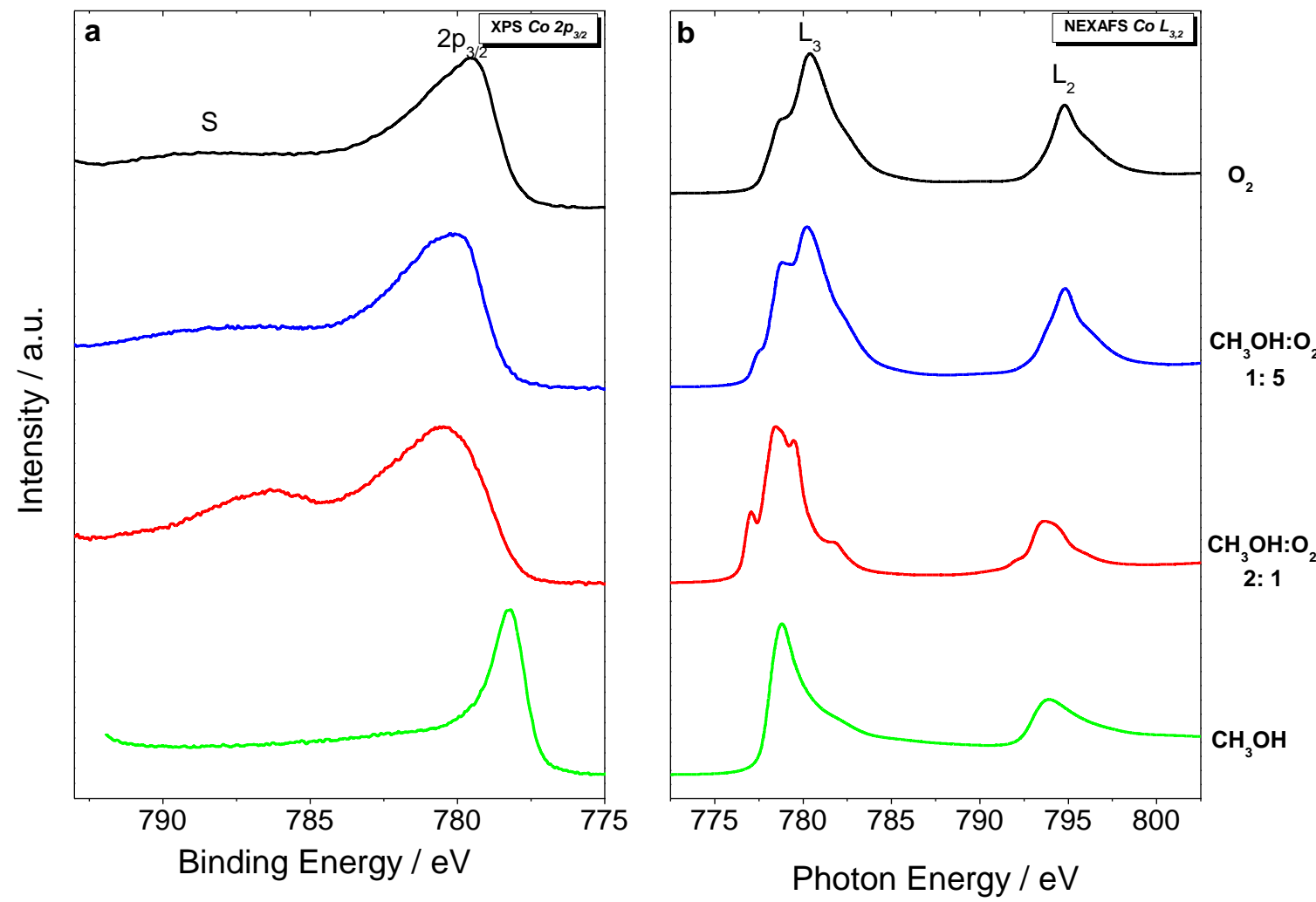

Fig. 1: (a) Co 2p $\mathrm{p}_{3 / 2} \mathrm{XPS}\left(h v=965 \mathrm{eV}\right.$ ) and (b) $\mathrm{Co}_{3,2} \mathrm{XAS}$ spectra of Co (0001) at $520 \mathrm{~K}$ under $0.2 \mathrm{mbar}_{2}, 0.3 \mathrm{mbar}^{\mathrm{C}} \mathrm{CH}_{3} \mathrm{OH}: \mathrm{O}_{2}=1: 5,0.2 \mathrm{mbar}$ $\mathrm{CH}_{3} \mathrm{OH}: \mathrm{O}_{2}=2: 1$ and 0.1 mbar $\mathrm{CH}_{3} \mathrm{OH}$.

Table 1: Normalized product selectivities and methanol conversion rates on cobalt, derived by on-line QMS results. Data are recorded at $520 \mathrm{~K}$ under $\mathrm{CH}_{3} \mathrm{OH}: \mathrm{O}_{2}$ reactant gas with mixture ratios 1:5, 2:1 and 1:0.

\begin{tabular}{|c|c|c|c|c|c|}
\hline & Sample type & Co $2 p_{3 / 2}$ main (eV) & Co $2 \mathrm{p}_{3 / 2}$ sat $(\mathrm{eV})$ & $015(e v)$ & Reference \\
\hline \multirow[t]{6}{*}{$\mathrm{Co}_{3} \mathrm{O}_{4}$} & $\mathrm{Co}_{3} \mathrm{O}_{4} / \mathrm{Co}\left(\begin{array}{llll}0 & 0 & 0 & 1\end{array}\right)$ & 779.6 & 788.5 Weak & $529.5-530.9$ & This work \\
\hline & Powder & $779.6 \& 780.5$ & $786-789.5$ Weak & 529.7, 531.3 (Shoulder) & [25] \\
\hline & & 779.9 & & & [28] \\
\hline & & 779.4 & & 529.2 & [29] \\
\hline & & 779.8 & & & [31] \\
\hline & & $780.0-780.3$ & 789.3 & & [19] and reference therein \\
\hline \multirow[t]{6}{*}{$\mathrm{COO}$} & $\mathrm{CoO} / \mathrm{C} \alpha(0001)$ & 780.6 & 786.3 Strong & $529.5-531.2$ & This work \\
\hline & $\mathrm{CoO} / \mathrm{C} \alpha(0001)$ & 780.1 & & 529.8 & [31] \\
\hline & Powder & 780.5 & 7862 Strong & $529.7,531.3$ (Shoulder) & [25] \\
\hline & $\cos \left(\begin{array}{llll}1 & 0 & 0\end{array}\right)$ & 780.4 & 786.7 Strong & 529.4 & [23] \\
\hline & Pownder & 780.3 & & & [29] \\
\hline & & $780.4-781.1$ & $787.0,787.3$ & & [19] \\
\hline \multirow[t]{2}{*}{ Co } & Co & 778.3 & Weak & & This work \\
\hline & $\operatorname{Co}(0001)$ & 778.3 & Weak & & {$[21,31]$} \\
\hline
\end{tabular}

The photoemission data of cobalt oxides published previously (see Table 1) provide the necessary basis for identification of the cobalt oxidation state [24-30]. In pure $\mathrm{O}_{2}$, the Co $2 \mathrm{p}_{3 / 2}$ photoemission peak at $779.6 \mathrm{eV}$ is accompanied by a weak, broad satellite (marked as $\mathrm{S}$ in Fig. 1a) characteristic of the $\mathrm{Co}_{3} \mathrm{O}_{4}$ spinel phase [24-26]. In agreement, the $\mathrm{L}_{3,2}$ edge fine structure (Fig. $1 \mathrm{~b}$ ) is very similar to that previously obtained on $\mathrm{Co}_{3} \mathrm{O}_{4}$ reference compounds $[27,28]$. Finally, the $\mathrm{Co} / \mathrm{O}$ atomic ratio calculated from the Co $2 p$ and $\mathrm{O} 1 \mathrm{~s}$ peaks was found $0.69 \pm 0.08$, within experimental error of the nominal value for $\mathrm{Co}_{3} \mathrm{O}_{4}(0.75)$. All spectroscopic results are consistent with the complete transformation of cobalt surface to $\mathrm{Co}_{3} \mathrm{O}_{4}$ when heated in $\mathrm{O}_{2}$ at
$520 \mathrm{~K}$. The thickness of the oxide layer exceeds $4 \mathrm{~nm}$ which is the estimated probing depth of the absorption spectra [31]. However, the cobalt crystal is still metallic in the bulk, since photoemission spectra showed no electrostatic charging, as would occur for the electrically insulating bulk $\mathrm{Co}_{3} \mathrm{O}_{4}$ oxide [26 and reference therein].

The spectroscopic characteristics undergo significant modification in oxygen-methanol mixtures. The Co $2 \mathrm{p}_{3 / 2}$ photoemission peak (Fig. 1a) is shifted to higher energies $(780.6 \mathrm{eV})$ and the satellite structure becomes broader and more intense, especially for $M R=2$. The difference curve (third spectra from the top), obtained after subtraction of Co $2 p$ spectra in pure $\mathrm{O} 2$ and reaction mixture $(\mathrm{MR}=0.2)$, 
Table 2: Relative product selectivities and methanol conversion rates on cobalt, derived by on-line QMS results. Data are recorded at $520 \mathrm{~K}$ under $\mathrm{CH}_{3} \mathrm{OH}: \mathrm{O}_{2}$ reactant gas with mixture ratios 1:5, 2:1 and 1:0.

\begin{tabular}{llllll}
\hline Methanol-to-oxygen ratio & Maximum methanol conversion $(\%)$ & $\mathrm{S}(\mathrm{CO})$ & $\mathrm{S}\left(\mathrm{CO}_{2}\right)$ & $\mathrm{S}\left(\mathrm{CH}_{2} \mathrm{O}\right)$ & $\mathrm{S}\left(\mathrm{H}_{2}\right)$ \\
\hline $1: 5$ & 26 & 6 & 58 & 13 & 0 \\
$2: 1$ & 2 & 25 & 13 & 35 & 16 \\
$1: 0$ & 14 & 47 & 0 & 9 & 11 \\
\hline
\end{tabular}

resemble very much that recorded on $\mathrm{MR}=2$ mixture. These are clear indications for partial reduction of $\mathrm{Co}_{3} \mathrm{O}_{4}$ under working conditions $[24,26]$. In pure methanol stream (bottom spectrum), the Co $2 \mathrm{p}_{3 / 2}$ peak at $778.3 \mathrm{eV}$ is indicative of cobalt in the metallic state [22,32], verifying that methanol is a very effective reducer for cobalt oxides [7]. The XAS spectra presented in Fig. 1b confirm the photoemission results. In particular, for $\mathrm{MR}=0.2$ the Co L-edges are the sum of $\mathrm{CoO}$ and $\mathrm{Co}_{3} \mathrm{O}_{4}$ reference spectra, as proved by the difference curve, indicating that under these conditions the surface stoichiometry can be written as $\mathrm{CoO}_{\mathrm{x}}$ (with $1<\mathrm{x}<1.33$ ). For MR $=2$ and pure methanol atmosphere, the Co L-edges are very much alike that found in previous measurements for $\mathrm{CoO}$ [27] and metallic cobalt [28], respectively. The strong resemblance of XPS and XAS data on our oxide films grown on Co single crystal, to previous results from $\mathrm{CoO}$ and $\mathrm{Co}_{3} \mathrm{O}_{4}$ bulk oxides is indicative of a similar chemical environment of $\mathrm{Co}$ and $\mathrm{O}$ ions in the two cases. However, it should be noted that the surface termination of the outermost layers might be considerably different in the two cases, as was recently showed for $\mathrm{Co}_{3} \mathrm{O}_{4}$ and $\mathrm{CoO}$ films grown on iridium [33,34].

It is evident that the composition of the gas phase significantly influences the surface chemical state of cobalt. The key in catalysis is to combine spectroscopic and catalytic data, in other words to correlate the surface chemical state to the catalytic activity and selectivity. Relative selectivities of the main products, as well as the methanol conversion, were calculated based on on-line QMS data (Table 2). Depending on the reaction conditions $\mathrm{CO}, \mathrm{CO}_{2}, \mathrm{CH}_{2} \mathrm{O}$, $\mathrm{H}_{2} \mathrm{O}$ and $\mathrm{H}_{2}$ were detected. Selectivities refer to constant temperature and pressure conditions $(520 \mathrm{~K}, 0.1-0.3 \mathrm{mbar})$ and are expressed as the percentage in the overall (CO, $\mathrm{CO}_{2}, \mathrm{CH}_{2} \mathrm{O}$ and $\mathrm{H}_{2}$ ) production. The maximum activity was obtained just after reaching $520 \mathrm{~K}(500 \mathrm{~K}$ for pure methanol) and afterwards gradual deactivation was observed, as was evident by the decrease of methanol consumption.

Comparison of the spectroscopic and catalytic data presented in Fig. 1 and Table 2 provide direct indications for the catalytic behavior of cobalt in oxide and metallic form. In particular for $\mathrm{MR}=0.2$, where $\mathrm{Co}_{3} \mathrm{O}_{4}$ is the dominant phase, the $\mathrm{CH}_{3} \mathrm{OH}$ consumption is high and total oxidation to $\mathrm{CO}_{2}$ is favoured. In contrast, for $\mathrm{MR}=2$, partial oxidation products $\left(\mathrm{CO}, \mathrm{CH}_{2} \mathrm{O}\right.$ and $\left.\mathrm{H}_{2}\right)$ are detected, accompanied with significantly lower methanol conversion rates (almost ten times). As showed in Fig. 1, in that case the pre-oxidized cobalt surfaces were reduced to $\mathrm{CoO}$-like oxide. Finally, in a pure $\mathrm{CH}_{3} \mathrm{OH}$ stream, metallic cobalt favours methanol decomposition to $\mathrm{CO}$ and $\mathrm{H}_{2}$. It is worth mentioning that above $500 \mathrm{~K}$, a high rate of coke deposition was observed on metallic cobalt, causing fast deactivation of this catalyst.

Combination of in situ spectroscopy and on-line gas phase analysis testifies to the dynamic response of the cobalt surface to the reaction mixture, indicating also the effect on the catalytic behaviour. However, for different MRs the reaction kinetics is considerably different, and therefore the assignment of catalytic reactivity exclusively to the cobalt oxidation state is not straightforward. In order to be able to evaluate the intrinsic catalytic properties of cobalt oxides, the comparison must be made under the same reaction mixture and preferably with similar reaction activity.

\subsection{The impact of cobalt oxidation state on the catalytic performance}

In thermodynamic equilibrium the composition of an oxide surface is determined by the gas phase chemical potential (temperature and oxygen partial pressure) [31]. However, in many cases, significant kinetic barriers inhibit the system from reaching the equilibrium. Therefore, depending on the initial state, metastable surface compositions can be often maintained under the same chemical potential. In this paragraph we will make use of this principle to compare the intrinsic catalytic properties of cobalt oxides under identical reaction conditions.

As shown in paragraph 3.1 , for $\mathrm{MR}=2$ the $\mathrm{Co}_{3} \mathrm{O}_{4}$ is completely reduced to $\mathrm{CoO}$, while limited reduction is observed for $M R=0.2$. Therefore, in order to compare different cobalt oxidation states under the same reaction conditions, rich in oxygen mixtures (low MRs) must be used. Prior to the reaction, cobalt was treated either in $\mathrm{H}_{2}$ or in $\mathrm{O}_{2}$ at $520 \mathrm{~K}$ to produce metallic and $\mathrm{Co}_{3} \mathrm{O}_{4}$ surfaces respectively. After pre-treatment the samples were cooled at room temperature, where the reaction mixture was introduced, followed by annealing at $520 \mathrm{~K}$. In figure 2, spectroscopic and catalytic data recorded on cobalt surfaces pretreated in $\mathrm{H}_{2}$ and $\mathrm{O}_{2}$ are presented. The deconvolution for the different contributions to the overall photoemission and absorption spectra are included in order to facilitate the discussion. In addition the Co:O stoichiometry calculated from $\mathrm{O} 1 \mathrm{~s}$ and $\mathrm{Co} 2 \mathrm{p}$ photoemission peaks are presented in Table 3. The reaction conditions (pressure, mixing ratio and temperature) were kept identical and spectra were recorded around 30 min after reaching reaction temperature, where a methanol conversion of $12 \pm 3 \%$ was measured for both 


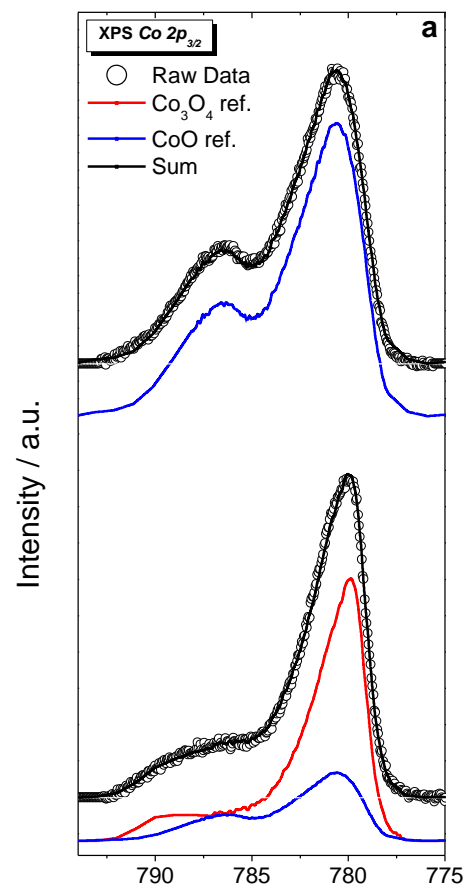

Binding Energy / eV
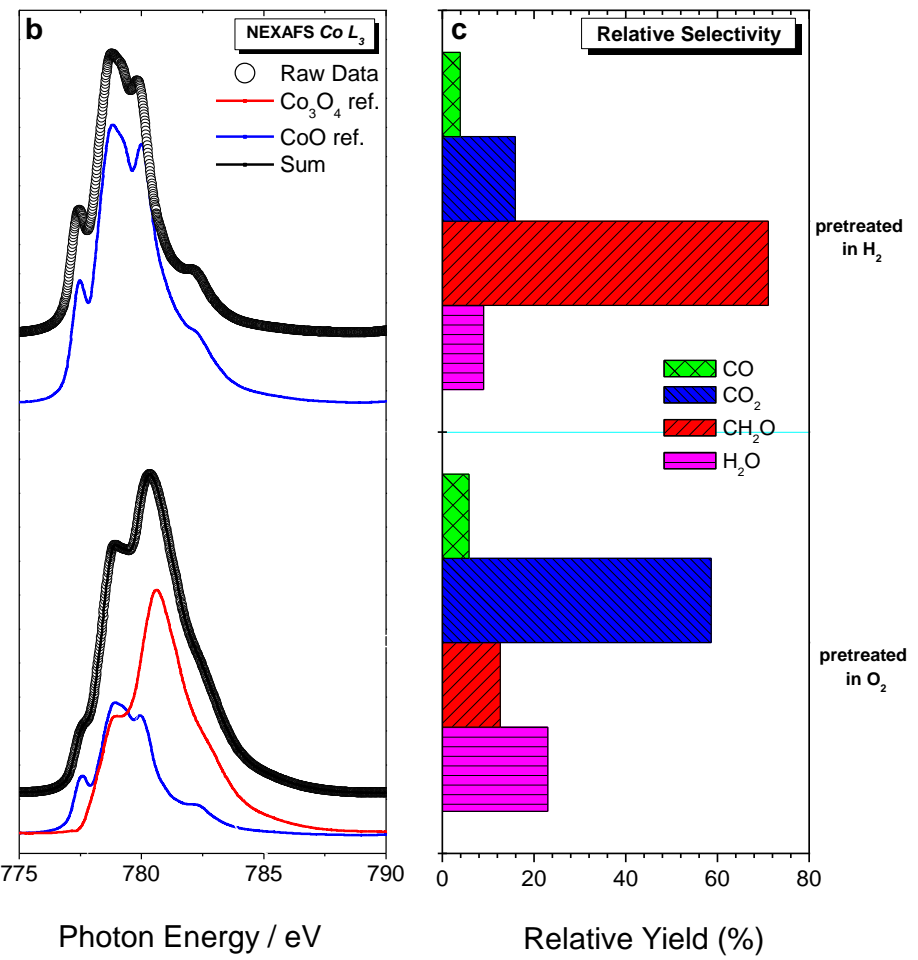

Fig. 2: (a) Co 2 $\mathrm{p}_{3 / 2}$ XPS ( $h v=965 \mathrm{eV}$ ), (b) $\mathrm{Co} \mathrm{L}_{3,2}$ NEXAFS spectra and (c) normalized product yields, of $\mathrm{H}_{2}$ and $\mathrm{O}_{2}$ pre-treated Co(0001). Spectroscopic and catalytic data are recorded at $520 \mathrm{~K}$, in $\mathrm{CH}_{3} \mathrm{OH}: \mathrm{O}_{2}=1: 5$, in total pressure of 0.3 mbar.

Table 3: The Co:O stoichiometry calculated from O 1 s and Co $2 p$ photoemission peaks. The reaction conditions were $\mathrm{CH}_{3} \mathrm{OH}: \mathrm{O}_{2}$ $=1: 5$, total pressure 0.3 mbar and temperature $520 \mathrm{~K}$.

\begin{tabular}{ll}
\hline Pretreatment & Stoichiometry Co:O \\
\hline Hydrogen & 0.98 \\
Oxygen & 0.73 \\
$\mathrm{Co}_{3} \mathrm{O}_{4}$ & 0.69 \\
\hline
\end{tabular}

samples. Therefore, the product yields presented in figure $2 \mathrm{c}$ are directly comparable since they refer to similar methanol conversion rates. Both photoemission (fig. 2a) and absorption (fig. 2b) spectra of cobalt clearly demonstrate that under the specific reaction conditions, metallic cobalt (pre-treated in $\mathrm{H}_{2}$ ) undergoes partial oxidation to $\mathrm{CoO}$, whereas the fully oxidized $\mathrm{Co}_{3} \mathrm{O}_{4}$ surface (pre-treated in $\mathrm{O}_{2}$ ) undergoes partial reduction to a 30/70 mixture of $\mathrm{CoO} / \mathrm{Co}_{3} \mathrm{O}_{4}$. This picture is conformed by the calculated stoichiometry in table 3 .

Depth dependent measurements of the Co $2 \mathrm{p}$ photoemission peaks did not show preferential surface localization of any of the oxides (see F1, supporting info). Therefore, a layered oxide structure is not supported and it is reasonable to refer to a mixed $\mathrm{CoO}_{\mathrm{x}}$ phase, with $\mathrm{x}$ varying according to the pretreatment. Comparison of spectroscopic results with product selectivities (fig. 2c) indicates that on the $\mathrm{CoO} / \mathrm{Co}_{3} \mathrm{O}_{4}$ surfaces total combustion to $\mathrm{CO}_{2}$ is the main reaction path, while on $\mathrm{CoO}$ partial oxidation to $\mathrm{CH}_{2} \mathrm{O}$ is favoured. Hydrogen formation was not detected and $\mathrm{CO}$ production was limited $(<5 \%)$ on both samples.

The $\mathrm{C} 1 \mathrm{~s}$ photoemission spectra recorded under reaction conditions are presented in figure 3a. Two carbon components are indicated at binding energies of 286.0 and $288.5 \pm 0.1 \mathrm{eV}$. The peak at $286.0 \mathrm{eV}$ is assigned to surface adsorbed methoxy groups $\left(\mathrm{CH}_{3} \mathrm{O}_{\text {ads }}\right)$, while the components at $288.5 \mathrm{eV}$ is characteristic of formate species $\left(\mathrm{HCOO}_{\mathrm{ads}}\right)$ $[5,6,32,33]$. The total coverage of carbon species, calculated from their XPS intensities, was found to be the same in the two cases $(7.5 \pm 0.5 \%)$. However, it is evident that the relative amount of methoxy and formate species depends on the pre-treatment, therefore on the oxidation state of the cobalt surface.

The $\mathrm{O} 1 \mathrm{~s}$ peak presented in figure $3 \mathrm{~b}$ consists of two oxygen components. The main at $529.6 \mathrm{eV}$ is due to lattice oxygen $\left(\mathrm{O}_{\text {lat }}\right)$ of cobalt oxides and its binding energy is not sensitive to the cobalt oxidation state, since $\mathrm{Co}_{3} \mathrm{O}_{4}$ and $\mathrm{CoO}$ have very similar energies (see Table 1) [25]. The broad oxygen shift about $1.9 \mathrm{eV}$ at higher energies cannot be attributed to intrinsic characteristics of cobalt oxides. In addition, depth depended measurements indicated that this component is mainly located on the surface (see F2, supporting info). Therefore, the oxygen peak at $531.5 \pm 0.1 \mathrm{eV}$ is related to oxygen-containing surface species $\left(\mathrm{O}_{\text {surf }}\right)$ on the cobalt oxide. Unfortunately it is difficult to directly determine the nature of $\mathrm{O}_{\text {surf }}$ species. In this energy range various adsorbed species containing oxygen are reported in 

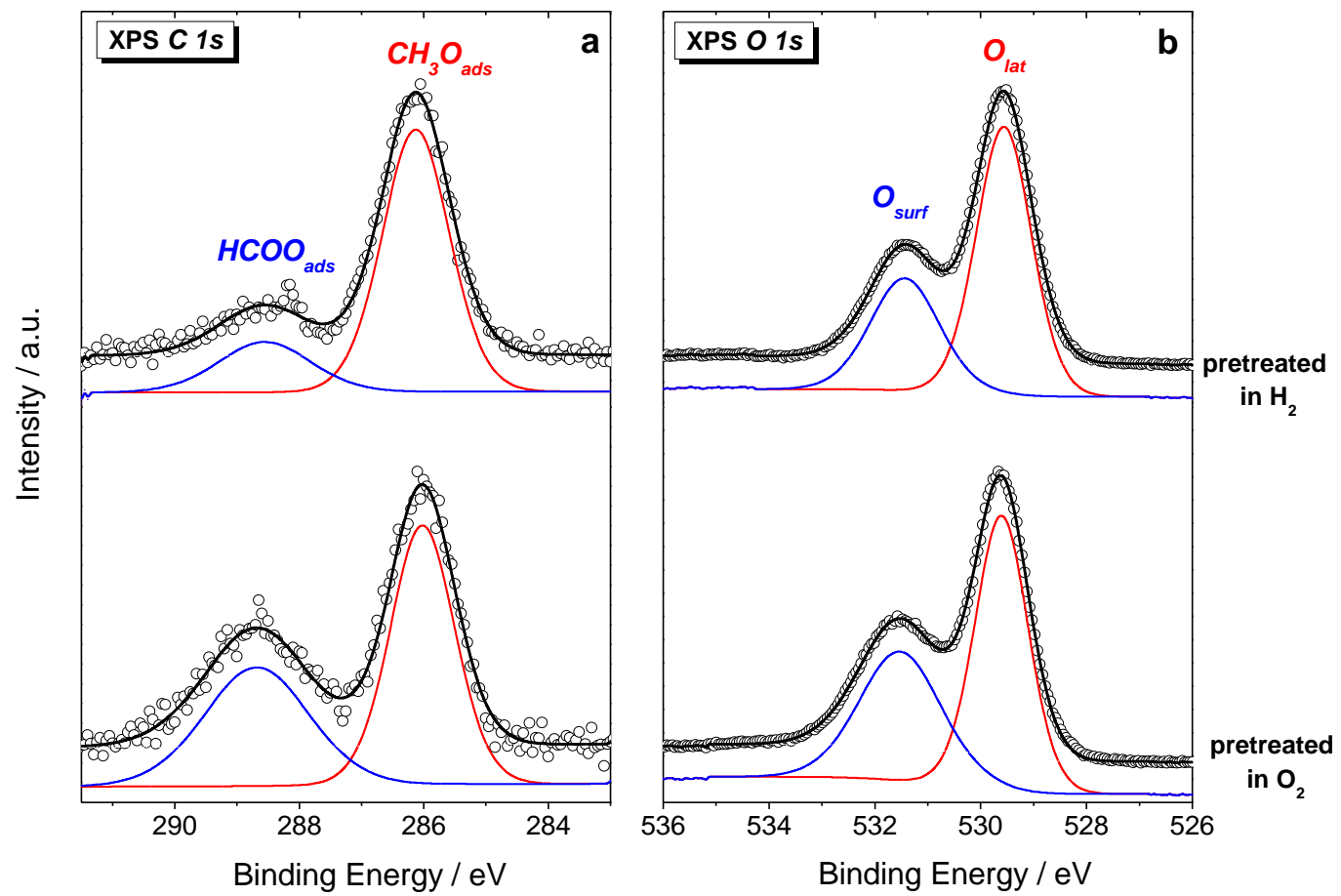

Fig. 3: XPS spectra of (a) $\mathrm{C} 1 \mathrm{~s}(h v=475 \mathrm{eV})$ and (b) $\mathrm{O} 1 \mathrm{~s}(h v=720 \mathrm{eV})$ of $\mathrm{H}_{2}$ and $\mathrm{O}_{2}$ pre-treated $\mathrm{Co}(0001)$ sample, the difference curve is the subtraction of the top from the bottom $\mathrm{O}$ 1s spectra. Data are recorded at $520 \mathrm{~K}, \mathrm{in}_{\mathrm{CH}} \mathrm{OH}: \mathrm{O}_{2}=1: 5$, in total pressure of $0.3 \mathrm{mbar}$.

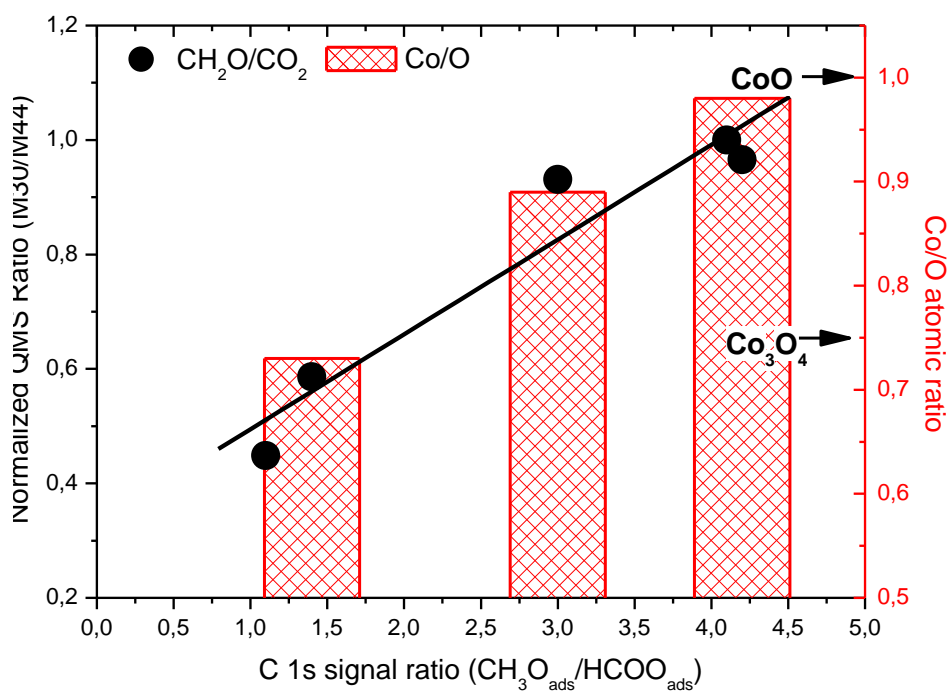

Fig. 4: The $\mathrm{CH}_{2} \mathrm{O} / \mathrm{CO}_{2}$ signal ratio (solid circles) from on-line $\mathrm{QMS}$, the cobalt oxide stoichiometry (red bars) and the $\mathrm{O}_{\text {ads }} / \mathrm{O}_{\text {lat }}$ intensity ratio (open circles) as a function of $\mathrm{CH}_{3} \mathrm{O}_{\text {ads }} / \mathrm{HCOO}_{\text {ads }}$ ratio (calculated from the analysis of $\mathrm{C}$ 1s photoemission peak). The data are collected on differently pre-treated cobalt surfaces (pure $\mathrm{O}_{2}, \mathrm{H}_{2}$ and $\mathrm{O}_{2} / \mathrm{H}_{2}$ mixture) under identical reaction conditions $\left(\mathrm{CH}_{3} \mathrm{OH}: \mathrm{O}_{2}=1: 5\right.$, at $520 \mathrm{~K}$ ).

Table 4: The Co:O stoichiometry calculated from photoemission results and normalized product selectivities as well as methanol conversion rate, derived by on-line QMS. Data are recorded on a $\mathrm{CoO}$ pretereated substrate at $520 \mathrm{~K}$ under $\mathrm{CH}_{3} \mathrm{OH}: \mathrm{O}_{2}$ reactant gas with mixture ratios 1:5 and $2: 1$.

\begin{tabular}{lllllll}
\hline $\mathrm{CH}_{3} \mathrm{OH} / \mathrm{O}_{2}$ & Stoichiometry $\mathrm{Co}: \mathrm{O}$ & Methanol conversion $(\%)$ & $\mathrm{S}(\mathrm{CO}) \%$ & $\mathrm{~S}\left(\mathrm{CO}_{2}\right) \%$ & $\mathrm{~S}\left(\mathrm{CH}_{2} \mathrm{O}\right) \%$ & $\mathrm{~S}\left(\mathrm{H}_{2}\right) \%$ \\
\hline $1: 5$ & 0.89 & 13 & 8 & 36 & 25 & 0 \\
$2: 1$ & 0.96 & 2.5 & 26 & 10 & 31 & 38 \\
\hline
\end{tabular}


the literature, like $\mathrm{O}-\mathrm{H}, \mathrm{C}-\mathrm{O}$ and $\mathrm{C}=\mathrm{O}$ species $[2,5,6]$. The peak at $531.5 \mathrm{eV}$ is definitely a convolution of oxygen related to $\mathrm{CH}_{3} \mathrm{O}_{\text {ads }}$ and $\mathrm{HCOO}_{\text {ads }}$ groups, without excluding other types of adsorbed oxygen. In order to testify for the existence or not of adsorbed oxygen species (additionally to formate and methoxy) the $\mathrm{O}_{\text {surf }}: \mathrm{C}$ atomic ratio was calculated using photoemission cross sections from reference [23] (the $\mathrm{O}_{\text {surf }}$ component of the overall $\mathrm{O}$ 1s peak derived by the deconvolution procedure shown in figure $3 b$ ). Assuming that the intensity of $\mathrm{O}_{\text {surf }}$ is a convolution of three kinds of oxygen species, namely; formate, methoxy and excess oxygen species $\left(\mathrm{O}_{\text {exc }}\right)$, the $\mathrm{O}_{\text {surf }}: \mathrm{C}$ ratio was used to calculate the intensity of $\mathrm{O}_{\mathrm{exc}}$ on the surface (see supporting info). It was found that around $30 \%$ of the $\mathrm{O}_{\text {surf }}$ intensity on $\mathrm{CoO} / \mathrm{Co}_{3} \mathrm{O}_{4}$ is due to $\mathrm{O}_{\text {exc }}$, while for $\mathrm{CoO}$ sample the $\mathrm{O}_{\text {surf }}$ component is solely due to methoxy and formate species. It should be noted that the nature of $\mathrm{O}_{\text {exc }}$ cannot determined accurately due to overlapping of several oxygen components in the $\mathrm{O} 1 \mathrm{~s}$ region.

One of the key observations arising by comparing the spectroscopic and catalytic results of figures 2 and 3, is that as the relative amount of $\mathrm{CH}_{3} \mathrm{O}_{\text {ads }}$ intermediates increases higher formaldehyde selectivity is observed. Since the reaction conditions were kept constant, the oxidation state of cobalt has apparently an effect on the relative amount of reaction intermediates on the surface and therefore to the selectivity. Figure 4 summarises the dependence of the $\mathrm{CH}_{2} \mathrm{O}$-to- $\mathrm{CO}_{2}$ QMS signal ratio (normalized to the maximum ratio), and the cobalt oxide stoichiometry (calculated from the photoemission results), in relation to the relative amount of methoxy species (calculated from the analysis of $\mathrm{C}$ 1s photoemission peak). The data are collected on differently pre-treated cobalt surfaces (pure $\mathrm{O}_{2}, \mathrm{H}_{2}$ and $\mathrm{O}_{2} / \mathrm{H}_{2}$ mixture) under identical reaction conditions $(\mathrm{MR}=0.2$ at $520 \mathrm{~K}$ ). According to this figure the formaldehyde selectivity (solid cycle points) is positively correlated to the relative abundance of $\mathrm{CH}_{3} \mathrm{O}_{\mathrm{ads}}$, and the $\mathrm{Co} / \mathrm{O}$ atomic ratio (red bars). The above presented results indicate that the reaction paths of methanol on cobalt catalysts critically depend on the surface oxidation state.

\subsection{Modification of the surface reactivity by chemisorbed species}

As has been indicated above for MR $=0.2$, the surface oxidation state influences the adsorbed reaction intermediates. In this paragraph the effect of the gas phase composition to the population and type of adsorbed species will be addressed. In order to avoid complications due to the modification of the surface oxidation state during reaction, a relatively stable substrate must be used to compare different MRs. Obviously, $\mathrm{Co}_{3} \mathrm{O}_{4}$ is not suitable for such studies since it undergoes fast reduction to $\mathrm{CoO}$ in $\mathrm{MR}=2$, as shown in paragraph 3.1. Therefore $\mathrm{CoO}$ pre-formed on the cobalt surface (see experimental section) was used. The surface stoichiometry calculated by the Co $2 p$ and $O 1$ s photoemission peaks, and the conversion-selectivity derived by QMS signal analysis, are presented in Table 4 . The initially prepeared $\mathrm{CoO}$ layer remain practically unaffected in $\mathrm{MR}=2$, but undergoes partial oxidation in $\mathrm{MR}=0.2$ (formation of $15 \% \mathrm{Co}_{3} \mathrm{O}_{4}$ at $520 \mathrm{~K}$ ). This is reflected to the lower $\mathrm{Co}: \mathrm{O}$ surface stoichiometry under 1:5 mixture. The on line QMS results showed that the methanol-to-oxygen mixing ratio affects both activity and selectivity of $\mathrm{CoO}$. In particular, at stationary reaction conditions, the excess of methanol in the mixture increases the selectivity to partial oxidation products $\left(\mathrm{CH}_{2} \mathrm{O}, \mathrm{CO}, \mathrm{H}_{2}\right)$, while in oxygen excess, relatively higher $\mathrm{CO}_{2}$ production was found. It should be noted that as compared to pure $\mathrm{CoO}$ phase under identical reaction condition (see figure 2), the $\mathrm{CO}_{2}$ selectivity is favoured here (36 instead of 21\%). This is not surprising since as was shown before higher oxygen stoichiometry enhances total oxidation reaction.

Temperature programmed reaction experiments (TPR) were carried out in order to monitor the evolution of surface intermediate species during the transition from nonreaction to reaction conditions. The surface temperature was increased from 320 to $520 \mathrm{~K}$ by $5 \mathrm{~K} / \mathrm{min}$. A set of spectra (Co $2 \mathrm{p}_{3 / 2}$, C $1 \mathrm{~s}$ and $\mathrm{O} 1 \mathrm{~s}$ ) were recorded approximately every $20 \mathrm{~K}$, and each spectrum takes about $50 \mathrm{sec}$ to record (variation of temperature during recording: $4 \mathrm{~K}$ ). In figure 5 we compare the development of different types of carbon species (taken from deconvolution of the $\mathrm{C} 1 \mathrm{~s}$ peak), with methanol consumption (calculated from on-line QMS) for MRs 0.2 and 2. Three carbon components at $285.1,286.0$ and $288.5 \pm 0.1 \mathrm{eV}$ were considered for the deconvolution of the overall $\mathrm{C} 1 \mathrm{~s}$ peak (see inset of figure 5). The $\mathrm{C} 1 \mathrm{~s}$ components at 286.0 and $288.5 \mathrm{eV}$ are due to $\mathrm{CH}_{3} \mathrm{O}_{\text {ads }}$ and $\mathrm{HCOO}_{\text {ads }}$ respectively, as explained in previous paragraph. The component at $285.1 \mathrm{eV}$, which vanishes at high temperatures, is assigned to $\mathrm{CH}_{\mathrm{x}}$ species attached on the $\mathrm{CoO}$ surface and is most probably originating from residual gas phase contaminants in the reaction chamber [5]. The amount of carbon is expressed as the percentage of the maximum carbon coverage (at about $350 \mathrm{~K}$ ).

According to figure 5, at low temperatures the surface was mainly covered by hydrocarbon and formate species, which are progressively disappearing as the temperature increases. Elimination of these species at 450 $\mathrm{K}$ marks the start up of catalytic activity as shown in figure 5a. In parallel, a significant population of $\mathrm{CH}_{3} \mathrm{O}_{\text {ads }}$ builds up, which reach a maximum at about $430 \mathrm{~K}$ just before the ignition of catalytic activity. Although these general characteristics account for both reaction mixtures there is a substantial difference between the two; in MR=0.2, a fraction of $\mathrm{HCOO}_{\mathrm{ads}}$ species remain adsorbed up to $520 \mathrm{~K}$, while in $\mathrm{MR}=2$ these species are practically removed at about $490 \mathrm{~K}$. In addition, in the lack of $\mathrm{HCOO}_{\mathrm{ads}}(\mathrm{MR}=2)$, the population of $\mathrm{CH}_{3} \mathrm{O}_{\text {ads }}$ species is enhanced (see fig $5 \mathrm{c}$ ).

The abundance of $\mathrm{CH}_{3} \mathrm{O}_{\text {ads }}$ in the expense of $\mathrm{HCOO}_{\text {ads }}$ species is in qualitative agreement with the increase of partial oxidation products and relatively low $\mathrm{CO}_{2}$ amounts produced for MR=2 (see Table 4). However, the higher population of methoxy species for $\mathrm{MR}=2$ compared 


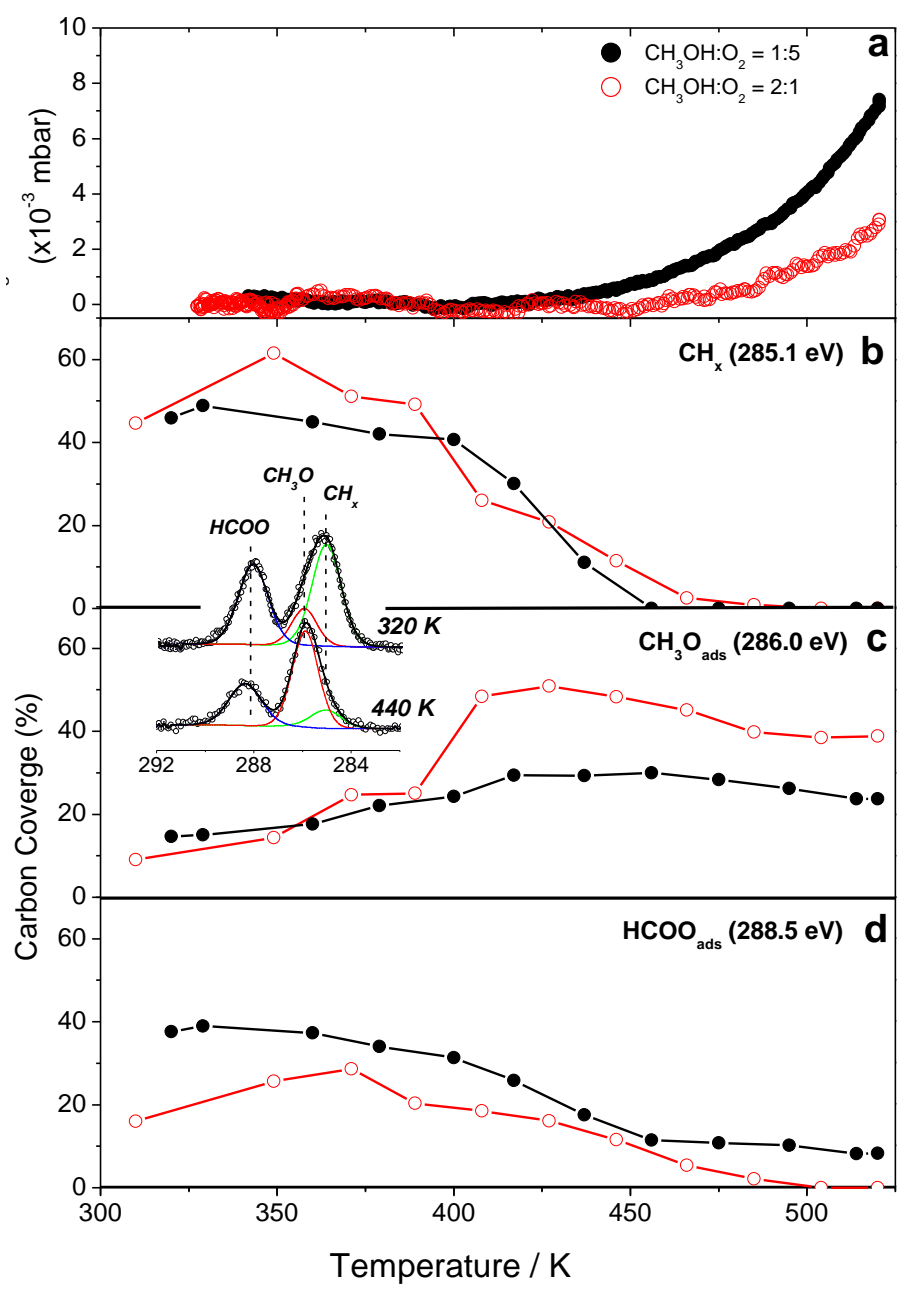

Fig. 5: (a) Methanol consumption, (b) hydrocarbon (c) methoxy and (d) formate species evolution as a function of temperature for $\mathrm{CoO} / \mathrm{Co}(0001)$ sample, in $\mathrm{CH}_{3} \mathrm{OH}: \mathrm{O}_{2}=1: 5$ (solid cycles) and $\mathrm{CH}_{3} \mathrm{OH}: \mathrm{O}_{2}=2: 1$ (open cycles). The heating rate was $5 \mathrm{~K} / \mathrm{min}$.

to $\mathrm{MR}=0.2$ (almost 2 times more $\mathrm{CH}_{3} \mathrm{O}_{\text {ads }}$ species per unit area), is not followed by equally high $\mathrm{CH}_{3} \mathrm{OH}$ conversion. On the contrary, the abundance of $\mathrm{CH}_{3} \mathrm{O}_{\text {ads }}$ in the expense of $\mathrm{HCOO}_{\mathrm{ads}}$ species is related to the decrease in methanol consumption. Residual carbon impurities or coke formation cannot be blamed for the lower activity in $\mathrm{MR}=2$ ratio, since only methoxy species are detected on $\mathrm{CoO}$ at $520 \mathrm{~K}$. Additionally, apart from oxygen atoms related to formates and methoxy, no additional surface adsorbed oxygen species $\left(\mathrm{O}_{\text {exc }}\right)$ are detected in both mixing ratios, as concluded from the $\mathrm{O}_{\text {surf }} \mathrm{C}$ ratio analysis. Therefore overpopulation of methoxy species is related to inhibition of the reaction, by poisoning the catalyst surface.

\section{Discussion}

The present results demonstrate that the active cobalt surface for methanol oxidation reaction is a mixture of $\mathrm{CoO}$ and $\mathrm{Co}_{3} \mathrm{O}_{4}$ oxides $\left(\mathrm{CoO}_{\mathrm{x}}\right)$, the relative portion of which depends on the starting compound (metal or oxide) and the composition of the $\mathrm{CH}_{3} \mathrm{OH} / \mathrm{O}_{2}$ reaction mixture. The dominant oxide in the mixture $\left(\mathrm{CoO}\right.$ or $\left.\mathrm{Co}_{3} \mathrm{O}_{4}\right)$ determines also the reaction path of methanol oxidation over the catalyst. The identification of active cobalt surfaces for partial and total oxidation of methanol to formaldehyde or carbon dioxide respectively, is important for addressing the selectivity issue when new cobalt containing catalysts are designed. Moreover, it is the elementary step towards a better understanding of the methanol reaction mechanism on cobalt and possibly on other oxide surfaces. The mechanism of methanol oxidation discussed in the literature, involves different reaction intermediates which lead to diverse products. Formation of methoxy species $\left(\mathrm{CH}_{3} \mathrm{O}\right)$ is believed to be the first common step for methanol adsorption on both metal and oxide surfaces [19 and ref therein]. In order for methoxy species to further react to $\mathrm{CH}_{2} \mathrm{O}$ or $\mathrm{CO}_{2}$, a proton must be abstracted from a methyl group or an oxygen atom must be attached on it respectively. The first process (proton abstraction) requires nucleophile surface 
sites while the second requires electrophilic oxygen adatoms [2].

The detection of reaction intermediates by in situ photoelectron spectroscopy depends on their surface coverage, which in turn is determined by their lifetime on the surface. Compared to previous methanol oxidation studies on copper and ruthenium catalysts $[4,7]$, the coverage of formate and methoxy species on cobalt oxide is greatly enhanced (from $<2$ on $\mathrm{Cu}$ to $c a .7 \%$ on $\mathrm{Co}$ ). This indicates that on cobalt oxide reaction intermediates experience longer lifetimes and are significantly more stable than on copper and ruthenium. As stated above surface oxygen is crucial for the transformation of methoxy species to $\mathrm{CH}_{2} \mathrm{O}$ or $\mathrm{CO}_{2}$. At low oxygen chemical potential, limited $\mathrm{O}_{2}$ access on the surface and therefore restriction of adsorbed reactive oxygen species is expected. Consequently the majority of surface sites is occupied by methoxy species and there is only a small fraction of sites containing adsorbed oxygen, leading to suppress of the catalytic activity. In the absence of adsorbed oxygen partial or complete dehydrogenation products $\left(\mathrm{CH}_{2} \mathrm{O}, \mathrm{CO}, \mathrm{H}_{2}\right)$ are expected to be formed according to the reactions:

\section{$\mathrm{CH}_{3} \mathrm{OH} \rightarrow \mathrm{CH}_{2} \mathrm{O}+\mathrm{H}_{2}$}

\section{$\mathrm{CH}_{3} \mathrm{OH} \rightarrow \mathrm{CO}+2 \mathrm{H}_{2}$}

This can explain the experimental results presented in figure 5, for MRs= 2 and 0.2 over $\mathrm{CoO}$. In both mixtures, gas phase $\mathrm{CH}_{3} \mathrm{OH}$ and $\mathrm{O}_{2}$ molecules are struggling for the same sites on the $\mathrm{CoO}$ surface. If adsorbed methanol $\left(\mathrm{CH}_{3} \mathrm{O}_{\text {ads }}\right)$ cannot react with oxygen, it irreversibly blocks the site. This is the case for $M R=2$. At high oxygen partial pressure (MR=0.2) molecular oxygen will be able to compete with methanol for the free sites, whereby the rate of $\mathrm{CH}_{3} \mathrm{O}_{\text {ads }}$ blocking is limited and higher methanol conversion rates are justified. In the later case the dominant reactions are:

$$
\mathrm{CH}_{3} \mathrm{OH}+1 / 2 \mathrm{O}_{2} \rightarrow \mathrm{CH}_{2} \mathrm{O}+\mathrm{H}_{2} \mathrm{O}
$$

$\mathrm{CH}_{3} \mathrm{OH}+3 / 2 \mathrm{O}_{2} \rightarrow \mathrm{CO}_{2}+2 \mathrm{H}_{2} \mathrm{O}$.

Apart from the gas phase oxygen chemical potential, the oxidation state of cobalt is also crucial for the reaction path, as showed in figures 2 and 4 . Under reaction conditions pure $\mathrm{Co}_{3} \mathrm{O}_{4}$ phase was not stable and a partially reduced $\mathrm{CoO}_{\mathrm{x}}(1<\mathrm{x}<1.33)$ surface oxide was formed. At high $\mathrm{x}$ valence of the $\mathrm{CoO}_{\mathrm{x}}$ oxide total oxidation is favoured, on the $\mathrm{CoO}$ partial oxidation to $\mathrm{CH}_{2} \mathrm{O}$ and on metallic $\mathrm{Co}$ decomposition to $\mathrm{CO}$ and $\mathrm{H}_{2}$. Analogous behaviour was also found for methanol oxidation on ruthenium [7]. High $\mathrm{CO}_{2}$ production rates on $\mathrm{Co}_{3} \mathrm{O}_{4}$ are related to equally high formate coverages on $\mathrm{CoO}_{\mathrm{x}}$ surface (see figure 5). Formate species might be formed by addition of one oxygen atom on adsorbed methoxy or formaldehyde species according to the schemes:

$$
\begin{aligned}
& \mathrm{CH}_{3} \mathrm{O}_{\mathrm{ads}}+\mathrm{O}_{\mathrm{ads}} \rightarrow \mathrm{HCOO}_{\mathrm{ads}}+2 \mathrm{H}_{\mathrm{ads}} \\
& \mathrm{CH}_{2} \mathrm{O}_{\text {ads }}+\mathrm{O}_{\mathrm{ads}} \rightarrow \mathrm{HCOO}_{\mathrm{ads}}+\mathrm{H}_{\text {ads }} .
\end{aligned}
$$

Both reactions require participation of electrophilic oxygen species, which involve cobalt ions with reduced electron density. As was previously showed for copper and ruthenium, the incorporation of subsurface oxygen into the first surface layers modifies the local electronic structure of metal ions and favours the formation of electrophilic oxygen. In additional it might cause surface lattice strain which relaxes by surface roughening and thus generates new active sites [2]. On cobalt the lattice strain and the local electronic structure near the surface tailor to the cobalt oxidation state, as was recently demonstrated by combined STM and LEED studies [29,30]. Theoretical studies on the $\mathrm{Co}_{3} \mathrm{O}_{4}$ (110) surface also predicted oxygen adsorption sites with different electron affinities [34]. It is however difficult to distinguish those sites on cobalt oxide surface, as was previously done for copper [4], due to the complexity of the $\mathrm{O} 1 \mathrm{~s}$ photoemission peak.

The similarities of methanol oxidation on cobalt, with previous studies on copper and ruthenium are quite profound. On copper the electron density of surface atoms is modified by sub-surface oxygen species [4], while for ruthenium, a "transient surface oxide $\left(\mathrm{RuO}_{\mathrm{x}}\right)$ " formed under specific reaction conditions, was found to be catalytically active [6]. On cobalt, oxidation is extended to several layers (>4 nm), so it is reasonable to refer to a thick surface oxide layer, at list under reaction conditions examined here. The stoichiometric $\mathrm{Co}_{3} \mathrm{O}_{4}$ oxide was only observed in pure oxygen atmosphere, while in the presence of methanol a mixture of $\mathrm{CoO} / \mathrm{Co}_{3} \mathrm{O}_{4}$ was always present. This is in fully analogy with the observations on ruthenium where a transient ruthenium oxide and not $\mathrm{RuO}_{2}$ was the active phase for methanol oxidation [6,7]. A simple comparison of the geometric structures of spinel $\left(\mathrm{Co}_{3} \mathrm{O}_{4}\right)$ and rocksalt $(\mathrm{CoO})$ oxides can provide additional insights into the reaction mechanism. The lattice oxygen of both oxides is face centered cubic (fcc) type [24,25]. Oxygen ions on the $\mathrm{Co}_{3} \mathrm{O}_{4}$ surface are highly mobile, compared to $\mathrm{CoO}$ supported by the ease of reducibility of cobalt oxides which has been shown to be in the order $\mathrm{Co}_{3} \mathrm{O}_{4}>\mathrm{CoO}$ [17]. It is reasonable to assume that the higher mobility of oxygen species in $\mathrm{Co}_{3} \mathrm{O}_{4}$ will assist their migration on the outermost surface layer when thermodynamic conditions are favourable. In the reduction step, $\mathrm{Co}_{3} \mathrm{O}_{4}$ can be an effective electron acceptor i.e. $\mathrm{Co}^{3+}+\mathrm{e}^{-} \rightarrow \mathrm{Co}^{2+}$, with oxygen ions providing the electronic charge for $\mathrm{Co}^{3+}$ reduction. According to the reactivity pattern discussed before for $\mathrm{Cu}$ and $\mathrm{Ru}$, when oxygen ions have less electronic charge, they become more electrophilic favouring methanol combustion. In high oxygen chemical potential $(\mathrm{MR}=0.2)$ reoxidation of $\mathrm{Co}^{2+}$ sites by gas phase oxygen will create a $\mathrm{CoO} / \mathrm{Co}_{3} \mathrm{O}_{4}$ mixture on the surface, as shown in figure 2 . The stability of the catalyst is determined by the capability of oxygen to incorporate into the cobalt surface, i.e. the ability to reoxidize the reduced sites with gas phase oxygen. The chemical 
potential of gas phase oxygen is a key factor in this process as showed here. In low oxygen chemical potentials complete reduction of $\mathrm{Co}_{3} \mathrm{O}_{4}$ to $\mathrm{CoO}$ will favoured building of nucleophilic oxygen and therefore selective reaction paths.

\section{Conclusions}

Combination of in situ photoelectron and absorption spectroscopy with on line mass spectrometry was employed to investigate methanol oxidation on cobalt in the mbar pressure range. The results showed that methanol is capable of reacting with both oxidized and metallic cobalt surfaces. The reaction path strongly depends on the cobalt oxidation state and the methanol-to-oxygen mixing ratio (oxygen chemical potential). The stoichiometric $\mathrm{Co}_{3} \mathrm{O}_{4}$ phase is stable only in oxygen atmosphere and is partially reduced under reaction conditions to a mixed $\mathrm{Co}_{3} \mathrm{O}_{4} / \mathrm{CoO}$ oxide.

\section{References}

[1] H. Topsøe, Journal of Catalysis 216 (2003) 155

[2] M. Salmeron, R. Schlögl, Surface Science Reports 63 (2008) 169

[3] G. Rupprechter, C. Weilach, Nanotoday 2 (2007) 20

[4] H. Bluhm, M. Hävecker, A. Knop-Gericke, E. Kleimenov, R. Schlögl, D. Teschner, V.I. Bukhtiyarov, D.F. Ogletree, M. Salmeron, J. Phys. Chem. B 108 (2004) 14340.

[5] S. Günther, L. Zhou M. Hävecker, A. Knop-Gericke, E. Kleimenov, R. Schlögl, R. Imbihl, The Journal of Chemical physics 125 (2006) 114709.

[6] R. Blume, M. Hävecker, S. Zafeiratos, D. Teschner, E. Vass, P. Schnorch, A. Knop-Gericke, R. Schlögl, S. Lizzit, P. Dudin, A. Barinov, M. Kiskinova, Physical Chemistry Chemical Physics 9, (2007) 3648.

[7] R. Blume, M. Hävecker, S. Zafeiratos, D. Teschner, A Knop-Gericke, R. Schlögl, P. Dudin, A. Barinov, M. Kiskinova, Catalysis Today, 124 (2007) 71.

[8] J. Zhang, J. Chen, J. Ren, Y. Sun, Appl. Catal. A 243 (2003) 121.

[9] M. Voß, D. Borgmann, G. Wedler, J. Catal. 212 (2002) 10.

[10] E. Iglesia, Appl. Catal. A 161 (1997) 59.

[11] G.P. Van der Laan, A.A.C.M. Beenackers, Catal. Rev. Sci. Eng. 41 (1999) 255.

[12] B. Kerler, A. Martin, A. Jans, M. Baerns, Appl. Catal. A 220 (2001) 243.

[13] Y. Zhang, K.J. Smith, Catal. Today 77 (2002) 257.

[14] L.B. Avdeeva, D.I. Kochubey, Sh.K. Shaikhutdinov, Appl. Catal. A 177 (1999) 43.

[15] J. Llorca, P.R. de la Piscina, J.-A. Dalmon, J. Sales, N. Homs, Appl. Catal. B 43 (2003) 355

[16] M. Ni, Dennis Y.C. Leung, M. K.H. Leung, International Journal of Hydrogen Energy 32 (2007) 3238

[17] S. Tuti, F. Pepe, Catal Lett 122 (2008) 196

[18] J. Jansson, A. E. C. Palmqvist, E. Fridell, M. Skoglundh, L. Osterlund, P. Thormahlen, V. Lange, Journal of Catalysis 211 (2002) 387

[19] M. M. Natile, A. Glisenti, Chem. Mater. 14 (2002) 3090

[20] K. Habermehl-Cwirzen, J. Lahtinen, P. Hautojärvi, Surf. Sci. $598(2005) 128$
Depending of the prevailing oxide phase the preferential reaction channels are: (a) for $\mathrm{Co}_{3} \mathrm{O}_{4}$, total oxidation to $\mathrm{CO}_{2}$ and $\mathrm{H}_{2} \mathrm{O}$, (b) for $\mathrm{CoO}$, the partial oxidation to $\mathrm{CH}_{2} \mathrm{O}$. Metallic cobalt is readily oxidized to $\mathrm{CoO}$ even in methanol rich environments, while in the absence of oxygen in the gas phase it favours methanol decomposition to $\mathrm{CO}$ and $\mathrm{H}_{2}$. The chemical potential of gas phase oxygen not only determines the surface oxidation state, but also the relative population of reaction intermediates $\left(\mathrm{CH}_{3} \mathrm{O}_{\mathrm{ads}}\right.$ and $\mathrm{HCOO}_{a d s}$ ). It can be argued that the formaldehyde formation is not only determined by the abundance of $\mathrm{CH}_{3} \mathrm{O}_{\text {ads }}$ species, but also by the availability of surface oxygen ions. Finally, comparison with previous studies on ruthenium and copper indicated that the transient surface oxide phase proposed earlier, might also account for the reactivity pattern on cobalt surfaces.

[21] O. Skoplyak, C. A. Menning, M.A. Barteau, J. G. Chen, J. Chem. Phys. 127 (2007) 114707

[22] M.P. Seah, in Practical surface Analysis. Vol 1 2nd ed.; D. Briggs, M.P. Seah Eds, Willey \& Sons, Chichester, UK (1992)

[23] J.J. Yeh, I. Lindau, At. Data Nucl. Data Tables 32 (1985) 1

[24] S.C. Petitto, E.M. Marsh, G.A. Carson, M.A. Langell, Journal of Molecular Catalysis A: Chemical 281 (2008) 49

[25] M. A. Langell, J. G. Kim, D. L. Pugmire, W. McCarroll, J. Vac. Sci. Technol. A 19 (2001) 1977

[26] H.A.E. Hagelin-Weavera, G. B. Hoflunda, D. M. Minahanb, G. N. Salaitac, Applied Surface Science 235 (2004) 420

[27] D. Bazin, I. Kovacs, L. Guczi, P. Parent, C. Laffon, F. De Groot, O. Ducreux, J. Lynch, Journal of Catalysis 189 (2000) 456.

[28] T. J. Regan, H. Ohldag, C. Stamm, F. Nolting, J. Luning, and J. Stohr, R. L. White, Phys. Rev. B 64 (2001) 214422.

[29] W.-H. Yang, M.H. Kim, S.-W. Ham, Catal. Today 123 (2007) 94.

[30] J. van Elp, J.L. Wieland, H. Eskes, P. Kuiper, G. Sawatzky, Phys. Rev. B 44 (1991) 6090.

[31] M. Abbate, J. B. Goedkoop, F. M. F. de Groot, M. Grioni, J. C. Fuggle, S. Hofmann, H. Petersen, M. Sacchi, Surf. Interface Anal. 18 (1992) 65.

[32] Nakamura, M. Haneda, H. Hamada, T. Fujitani, J. Electron Spectrosc. Relat. Phenom. 150 (2006) 150.

[33] W. Meyer, D. Hock, K. Biedermann, M. Gubo, S. Mu"1ler, L. Hammer, and K. Heinz, Phys. Rev. Let. 101, (2008) 016103.

[34] W Meyer, K Biedermann,M Gubo, L Hammer and K Heinz, J. Phys.: Condens. Matter 20 (2008) 265011.

[35] M. Batzill, U. Diebold, Progress in Surface Science 79 (2005) 47

[36] M. Shen, F. Zaera, J. Phys. Chem C 112 (2008) 1636

[37] T. Kawabe, K. Tabata E. Suzuki, Y. Nagasawa, Surface Science, 482-485_(2001) 183

[38] P. Broqvist, I. Panas, H. Persson, Journal of Catalysis 210, (2002)198 